\title{
Detection and Analysis of Annual Precipitation Change Points in West of Iran
}

\author{
Ramin Beedel \\ Faculty member at Soil Conservation and Watershed Management Research Department, Kermanshah \\ Agricultural and Natural Resources Research and Education Center, AREEO, kermanshah, Iran. \\ airssc2@gmail.com
}

\begin{abstract}
Precipitation is one of the sensitive and essential factors in water resources management. Decreasing variations in the amount of precipitation in any time scale and its distribution, as well as smaller land area per rainfall, could affect many water resources` planning, specially groundwater utilization. In this study, detecting change points and the annual precipitation trend in Western Iran and in the geographical area of Kermanshah, Ilam, Lorestan, Kurdestan, and Hamedan provinces, have been studied. For this purpose, rainfall data of 5 synoptic meteorological stations with statistical period of at least thirty years was used. Having created databases associated with research objectives, statistical data of the stations was explored in terms of quality, accuracy, outlier data, normality and homogeneity. Then, the cumulative sum control chart (CUSUM) technique ws utilized to detect change points and break in data time series, and also the Mann-Kendall test was used to examine the trend and the change points. The findings of this study suggested that concurrent trend and change points were not definite in a time series and the cumulative sum control chart technique had more accuracy and reliability compared to Mann-Kendall test in such a way that the years with significant change point were almost in common with the two methods mentioned in Kermanshah (1996-97), Ilam (1998-99), Sanandaj (1998-99) stations and Khorramabad and Hamedan stations did not have change points. Whereas, using Mann-Kendall test, these annual change points had an average probability in Kermanshah stations (2005-2006), after the change of location in Ilam (1998-1999) and Khorramabad (2004-2005) stations, and lacked the change point in Sanandaj (1987-1988) and Hamedan stations indicating a basic difference in formula structure and the method of calculation. The point at issue in the years associated with the change points in the two methods was that these points coincided with and corresponded to the years with highest maximum temperature (1998), the highest frequency of temperature change point (1998), and the periods of moderate and severe drought (1996-1997 and 1998-1999) in Western Iran. Therefore, and based on the results of annual precipitation trend with only Sanandaj station having downward trend, it must be acknowledged that, despite fluctuations in annual precipitation amount, these changes did not result in inappropriate and irreversible conditions but using improper methods of surface and underground water resource management in Western Iran could be the cause for concern more than drop in precipitation.
\end{abstract}

Keywords: Change point, Cumulative sum ,Precipitation, Trend analysis, Western Iran.

\section{Overview}

\subsection{Introduction}

Precipitation is one of the vital factors in environmental issues. Awareness of its changes in arid and semi-arid regions of the country is of considerable significance because a large part of water supply required for agricultural activities is produced by atmospheric precipitation. At least for the past two decades, precipitation conditions have undergone changes in terms of amount and temporal and spatial distribution in the Western Iran, having little or no historical records. Understanding the reason behind this, is not the basis of this study, but understanding the trend and time of these changes is the main purpose of this research in terms of systematicity and the probable time of change in precipitation behavior and amount on an annual scale. In the Western Islamic Republic of Iran, rainfed lands that rely on autumn rainfall cover a large surface area and the number of groundwater reservoir and seasonal springs affected by precipitations, which are one of the sources of irrigation supplies of agricultural lands, are considerable; awareness of the precipitation behavior status in the past and its bias in the future is of enormous significance and justifies conducting such a research.

\subsection{Analysis of Resources}

This study aimed to analyze the annual precipitation change points in synoptic meteorological stations in five western provinces in the country, and then described some of the history of similar activities at home and abroad.

Kürbis et al. (2009) investigated the trend of extreme temperature, dew point, and precipitation in the Central Europe. The result of this study highlighted that freezing winters for Germany and Prague occurred in the mid twentieth century, while hot summers have had an increasing trend. They argued that the maximum summer temperature could be analyzed using linear changes in the mean and standard deviation. Precipitation in this region did not show any trends, but dew point changed from a peak in the 1960s to a low amount in the 1970s. Jianting 
et al. (2010) studied the spatial and temporal changes of daily rainfall in Haihe river basin during the period of 1958-2007 using Mann-Kendall test. They found that throughout the basin, precipitation during the above statistical period, has declined except for spring and it was significant in summer season and this downward trend heightened after the year 1980. Also, precipitation in this region has decreased from south to north and from coastal areas to inland areas. Soltani et al. (2013) conducted a statistical analysis of long-term precipitation in winter in Gorgan season in the period 1956-2005 using Mann-Kendall test and time series techniques. They found that data trend using multiple regression method showed a weak decreasing trend at the end of the statistical period, while sequential Mann-Kendall test has also recognized negative trends without any jumps and breaks in the data values. Li et al. (2013) analyzed the precipitation in the Beijing region with the time series of 300 years using sequential Mann-Kendall test. The results of this study suggested that there was a significant incremental trend at the $\% 5$ level in the whole time series which had no turning points. Gallagher et al. (2013) studied the detection of change points in climatic time series with long-term trend related to the two sets of temperature data in the continental America and Jacksonville region in Illinois state. They used simple homogeneity test as well as student's t-test to identify change points. Khapalova et al. (2013) analyzed the change points of the average precipitation in the northern, tropical, and southern latitudes of the earth over the past 100 years. They showed that there was a significant change in the precipitation in the northern and southern latitudes in the year 1944, with no changes in tropical latitudes.

Zarenistanak et al. (2014) analyzed and detected the change points of annual and seasonal precipitation data, mean temperature, maximum temperature and the minimum temperature of time series of 89 stations in south-western Iran. Having used three methods of Petit, sequential Mann-Kendall, and ranked Mann-Kendall tests, they found that there were significant change points in the year 1990 related to average, maximum, and minimum temperature. Shirvani(2015a) used parametric student's t-test and non-parametric Mann-Whitney U test during the years 1951-2013. He found that both of the above methods, identified the year 1992 as the change point in time series.

Shirvani (2015b) detected change points in 18 synoptic stations in Iran during the years 1951-2010 using Mann-Whitney non-parametric test. The results of this study indicated that change points in the years 1997, 1984, 1967, and 1994 existed in the data of the stations of Kerman, Urumiye, Shahroud, and Tabriz.

Suh and Kim (2015) carried out the detection of change points using Bayesian analysis in the days along with tropical nights (the day with a minimum daily temperature above $25^{\circ} \mathrm{C}$ ) in the time series of 50 years in five major cities of South Korea. The results of this study indicated that the year 1993 was regarded as the change point in the three cities of Seoul, Incheon, and Diego and could be associated with a significant decade-long change in East Asian summer monsoon in mid-1990 and rapid urbanization.

Fu et al. (2015) used Wilcoxon signed-rank test to identify the change points of precipitation indices in the Western Canada. The findings of this study revealed that there was an increasing trend in the number of humidity days and maximum daytime rainfall, and a decrease in the number of dry days and detected change points accordingly.

Aminikhanghahi and Cook (2017) analyzed the detection methods of change points in time series. In classifying the available methods, they used supervised and unsupervised algorithms to evaluate and introduce points.

Siti et al. (2017) used the change point analysis to detect the potential for significant changes in mean annual rainfall, temperature, and relative humidity over 25 years using CUSUM and Bootstrap methods in Malaysia. They used CUSUM method to analyze data and trend pattern, and the Bootstrap method to determine the type of change. The findings of this study suggested that the changes in data values have occurred in the years 1991, 2001, and 2002.

Dibal et al. (2017) performed a statistical analysis of the change point in time series of weather temperature and precipitation in Nigeria's Coffee Research Institute. Using CUSUM method, they found that there was one change point in the amount of rainfall and several change points in the amount of minimum temperature while maximum temperature lacked any change points.

Khosravi et al. (2017) analyzed and identified the trend of rainfall fluctuations in arid and semi-arid regions of Iran. They used 22 rain gauge stations in Fars province during the statistical period of $1972-2011$ and found that apart from Monjeh station, other stations had downward precipitation trend. The findings of this study reflected that on the basis of Petit and standard normal homogeneity tests, only the stations of Aliabad Khafr, Tangab, and Ramjerd in winter had change points in their time series.

Palaniswami and Mutiah (2018) performed trend analysis using Mann-Kendall test and Sen's slope for monthly, seasonal, and annual data of temperature as well as maximum daily precipitation at annual, seasonal scales and total annual rainfall. The results of this study suggested that mean annual temperature as well as seasonal and monthly maximum and minimum temperatures had a significant growing trend. The change points of maximum and minimum temperature were found to be in the years 1985, and 2001, and also 1987, and 2013, 
respectively. Annual mean temperature also had change points in the years 1983 - 1988 and 2000 - 2004 at 100\% confidence intervals. Yogesh et al. (2018) analyzed the rainfall trend and detected change points in Andhra Pradesh and Telangana states of India using parametric methods like Mann-Whitney test, Kruskal-Wallis test, and Median test as well as certain non-parametric tests.

Kundu and Mondal (2019) analyzed the along-term precipitation trend and change points in West Bengal, India for 102 years at 18 stations. The results of this study suggested that the probable three-year period had the change point of annual precipitation, including years 1956, 1967, and 1952 related to stations located at the north, south, and west of Bengal. Yu and Ruggieri (2019) analyzed the change point in global temperature data. They used Bayesian algorithm method to identify the location of change points in five types of time series of surface temperature anomaly. The findings of this study demonstrated that the change points of these data took place in the time series of 1902 - 1917, 1936 - 1945, and 1963 - 1976 and these points were higher in number in the ocean than in the land and they were also more in the southern latitudes than the northern latitudes.

Fearnhead and Rigaill (2019) introduced a method for detecting change points in time series with outlier points. They argued that loss function would be very data-resistant and accordingly, they developed a proper dynamic programming algorithm that could be used online for analyzing data like that of water well. Asgari et al. (2019) analyzed the change points of annual discharge in Golestan province in 20 hydrometric stations with 34 statistical years. They defined the duration and extent of change points and then, analyzed their relationship with precipitation and temperature. The findings of this study revealed that there was a positive significant correlation at the level of $\mathrm{P}<0.001$ between discharge and precipitation, and there was an insignificant correlation between discharge and temperature, and the number of decreasing significant change points were significantly higher than increasing change points and major changes happened in the years 1994, 1995, and 1998 in 4, 5, and 3 stations, respectively.

Zhou et al. (2019) studied certain non-parametric methods to compare the capability and accuracy of identifying change points. They used Pettitt method, Cramer two-sample test, and CUSUM test. The results of this study highlighted that the above methods had different behavior and all of them significantly estimated the distribution of the location of change point near the end of the sample. They also used the time series of annual maximum runoff for 4 stations on the Yangtse river in China to test the preference of methods over real data and showed that Cramer test produced best results, however, all three methods had low deviation and ability in detecting change points at the end of time series.

\section{Studied Area}

This study was geographically located in the west of Iran in the boundaries of Kermanshah, Ilam, Lorestan, Kurdestan, and Hamedan provinces and was performed using the rainfall data of 5 main synoptic meteorological stations according to Figure 1.

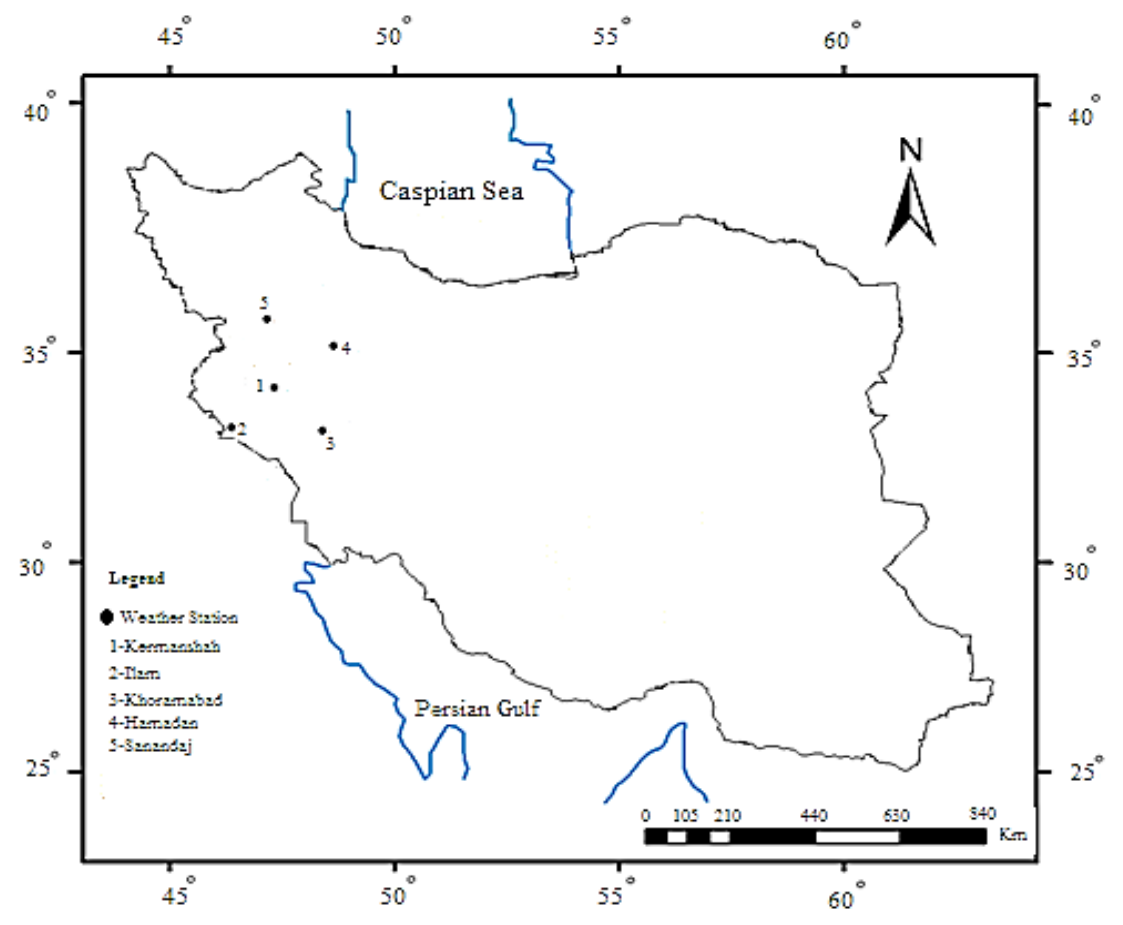

Fig 1.Geographical location of stations 


\subsection{Data}

\section{Data and Methodology}

Most of the research conducted on precipitation has been aimed at predicting this variable and at planning water resources more favorably. The fear of dehydration and drought in its various forms is the prospect of precipitation that is, in fact, a scientific move to adjust the management response to different climatic conditions. Using the rainfall data of 5 main synoptic meteorological stations with at least 30 statistical years, this study analyzed and detected the potential change points of precipitation on annual scale. The specifications of the stations mentioned are presented in Table 1.

Table 1: Specification of meteorological stations and statistical study period

\begin{tabular}{|c|cc|cc|c|c|c|}
\hline Data Period & \multicolumn{2}{|c|}{ Latitude } & Longitude & latitude(m) & Station Name & Order \\
\hline $1951-2015$ & 21 & 34 & 09 & 47 & 1318.6 & Kermanshah & 1 \\
\hline $1986-2015$ & 38 & 33 & 26 & 46 & 1337 & Ilam & 2 \\
\hline $1951-2015$ & 26 & 33 & 17 & 48 & 1147.8 & Khorramabad & 3 \\
\hline $1980-2015$ & 20 & 35 & 00 & 47 & 1373.4 & Sanandaj & 4 \\
\hline $1968-2015$ & 52 & 34 & 32 & 48 & 1741.5 & $\begin{array}{c}\text { Hamedan Airport } \\
\text { Shahid Nozheh }\end{array}$ & 5 \\
\hline
\end{tabular}

\subsection{Methodology}

The research methodology included two stages, namely the preparation and analysis of data quality, and the analysis of the change points of data that have been treated in detail in the following.

\subsubsection{Data Preparing and the Analysis of Data Quality}

After receiving annual rainfall statistics from the websites of Meteorological Organizations of Iran's western provinces, a database of precipitation data was created in Excel software with dedicated pages for each station. Then, the three subjects of, a) normality using the methods proposed by Shapiro-Wilk (1968), Anderson- Darling (1954), Lilliefors (1967), and Jarque-Bera (1987), b) homogeneity using the methods of Pettitt's test (Pettitt, 1979), standard normal homogeneity (Alexanderson, 1986), Buishand's test (Buishand, 1982), Von Neumann's test (Neumann, 1941), and c) the analysis of outlier data using Grubb's test (Grubb, 1969), Dixon's test (Dixon, 1950), and Z-score were explored. Therefore, data quality assessment was carried out to increase initial knowledge about breakpoints and possible mutations in data time series.

\subsubsection{The Analysis of Change Points}

It is important to understand the time of change to study the behavior change of rainfall variable in data time series in which a trend is set. Of course, there are many factors that cause this change of break including climatic conditions, human intervention in the surrounding environment such as extensive urban construction, elimination of vegetation, creation of large water zones due to dam, and the change of land use on a large scale. Station shifting and changing measurement equipment could also be responsible for the change of variable behavior. In this study, the detection of change points was carried out using several methods including the analysis of change points with cumulative sum chart (CUSUM) and sequential Mann-Kendall test .

\subsubsection{The Cumulative Sum Control Chart and the Analysis of Change Points}

In this method, the data of time series is calculated during the following formulaic steps and then the cumulative chart is plotted. On this chart, the points that indicate significant break and/or mutation, will be visible with the change of direction that occurs at continuous points in the time series.

If we have time series with $n$ number of data $\left(x_{1}, x_{2}, \ldots x_{n}\right)$, cumulative sum control chart is obtained by calculating the mean of data and $\mathrm{s}_{\mathrm{i}}$ statistics as the following (Taylor, 2000).

$$
\begin{aligned}
& X=x 1+x 2+\ldots x n / n(9) \\
& s i=s i-1+(x i-X) \text { for } i=1,2, \ldots n .(10)
\end{aligned}
$$

Plotting $S_{i}$ values over the length of statistical period, the above chart is obtained where, if examined, change points could be detected. 


\subsubsection{Sequential Mann-Kendall Method}

This method is also known as the ranked and serial correlation and is used to determine the trend and recognize the start time of the process (Sneyers, 1990). In a time series with $n$ number of data, each element has been compared with its previous element by examining the condition of $y_{i}>y_{j}$ and given that $i>j$, and then the $t-$ statistic is computed as follows (Aesawy, 1998),( Mann1945),( Kendall 1975).

$\mathrm{t}=\sum_{i=1}^{n} n_{\mathrm{i}}(11)$

$\mathrm{E}(\mathrm{t})=\frac{n(n-1)}{4}(12)$

$\operatorname{Var}(\mathrm{t})=\frac{n(n-1)(2 n+5)}{72}(13)$

$u(\mathrm{t})=[\mathrm{t}-\mathrm{E}(\mathrm{t})] / \sqrt{\operatorname{Var}(t)}(14)$

$u_{i}^{\prime}=-u\left(t_{i}^{\prime}\right)(15)$

$\mathrm{t}=$ test statistic

$\mathrm{n}=$ total number of data with the above condition

$\mathrm{E}(\mathrm{t})=$ expected value

$\operatorname{Var}(\mathrm{t})=$ variance

If $u(t)$ reaches a high value, it means that there is a trend in time series, and if we perform computational steps from the end of time series, $u^{\prime}(t)$ would be produced and the intersection point of these two values on the corresponding time series chart indicates the start time of the process.

The results obtained from using each one of these methods in the stations have been presented as follows:

\section{Kermanshah Station}

In Figure 2 which presents the results obtained from the application of Mann-Kendall method over annual precipitation, the curves for statistics $u$ and $u^{\prime}$ had a trivial intersection point in the years 2005 - 2006 and the status of the changes in chart indicated the uncertainty about trends in annual precipitation time series.

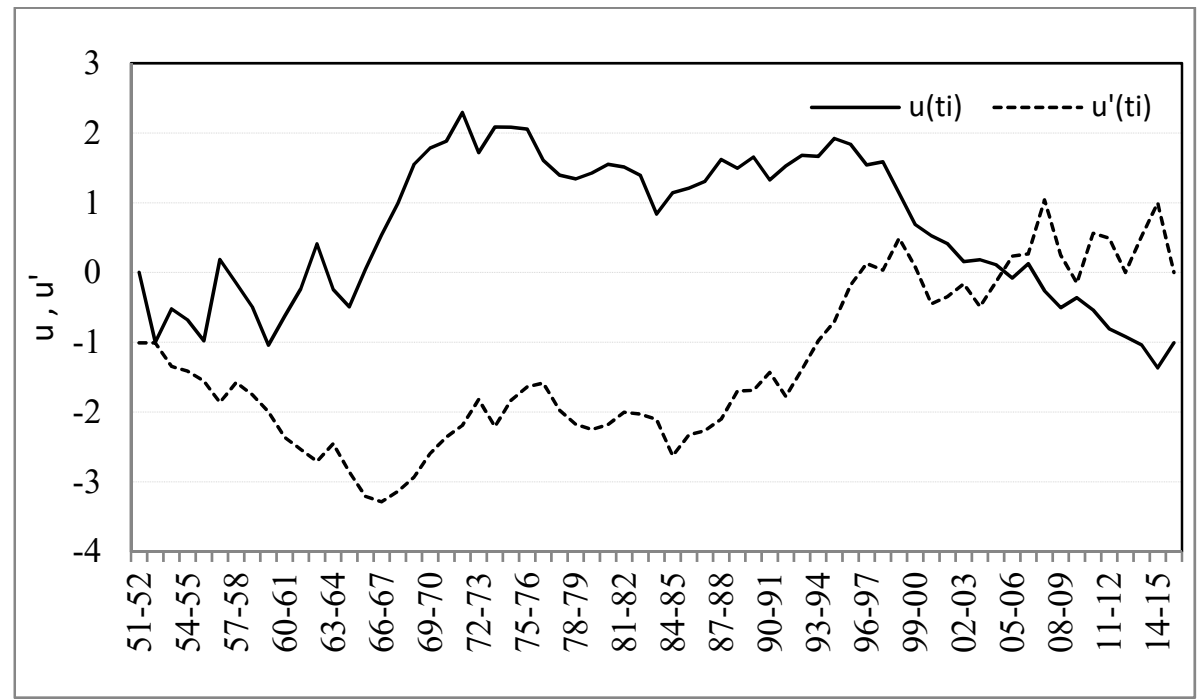

Fig 2. Trend and Change Point Analysis of Kermanshah Station by Sequential Mann-Kendal Method Annual Precipitation (1951-2016)

Figures 3 and 4 and also Table 2 display the results of cumulative sum control chart and the analysis of change points in the form of graphical and tabular representation at 95\% confidence level and with high and low confidence intervals. While confirming the lack of trend in this method, the year 1996 - 1997 (equivalent to years 1375 - 1376 in Solar Hijri Calendar) has been demonstrated as the beginning of change in the behavior of this time series (to obtain A.D or Gregorian Calendar, add the number 621 to Solar Hijri Calendar). 


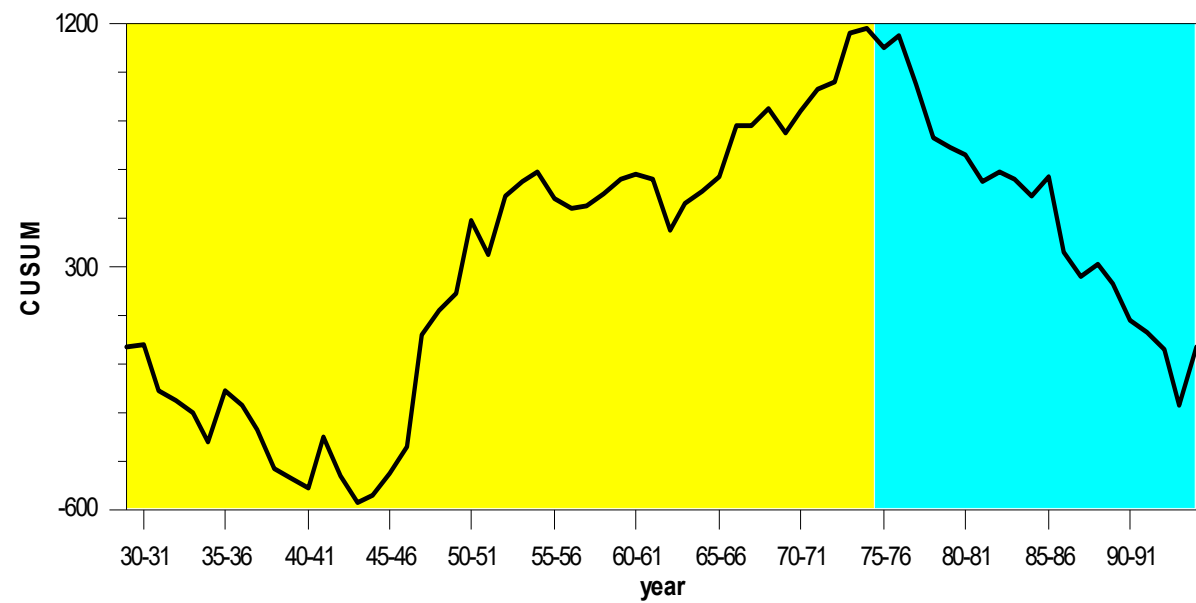

Fig 3. Annual precipitation change point of Kermanshah station by CUSCUM *** (change point at 1375-76 in Solar Hijri Calendar equal to 1996-1997 to AD Calendar)

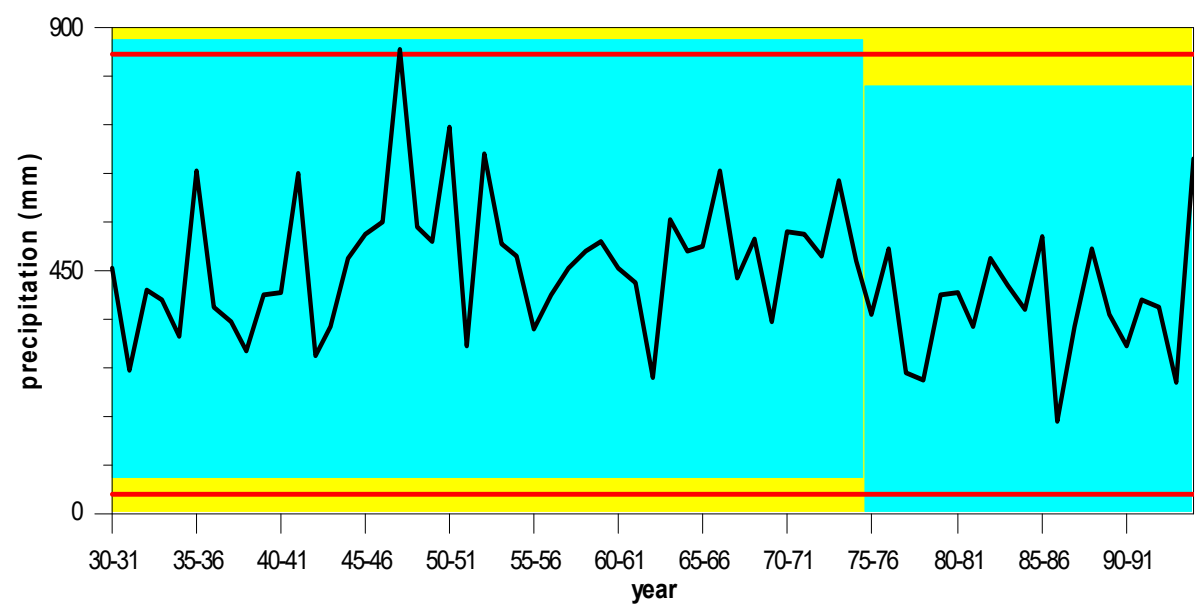

Fig 4. Analytical Chart of Annual Precipitation Change Point of Kermanshah Station (1330- 1395 to Solar Hijri Calendar) *** (change point at 1375-76 in Solar Hijri Calendar equal to 1996-1997 to AD Calendar)

Tab 2. Results of Significant Changes for annual precipitation of Kermanshah station

\begin{tabular}{|c|c|c|c|c|c|}
\hline \multicolumn{5}{|c|}{ Table of Significant Changes for precipitation } & $\begin{array}{l}\text { n } \\
\text { ence Interval = 95\%, }\end{array}$ \\
\hline year & Confidence Interval & Conf. Level & From & To & Level \\
\hline $75-76$ & $(52-53,80-81)$ & $98 \%$ & 466.74 & 381.52 & 1 \\
\hline
\end{tabular}

Note: year $=1996-1997$ and Confidence Interval $=1973-74,2001-2$ (A.D Calendar)

\section{Ilam Station}

The chart of annual rainfall trend of this station that has been reflected in Figure 5 using sequential Mann-Kendall method, indicated the lack of trend, however, using analytical and cumulative chart methods, it had a strong probability of change points in the years 1998 - 1999 (equivalent to 1377 - 1378 in Solar Hijri Calendar) that has been shown in Figures 6 and 7 and also Table 3. 


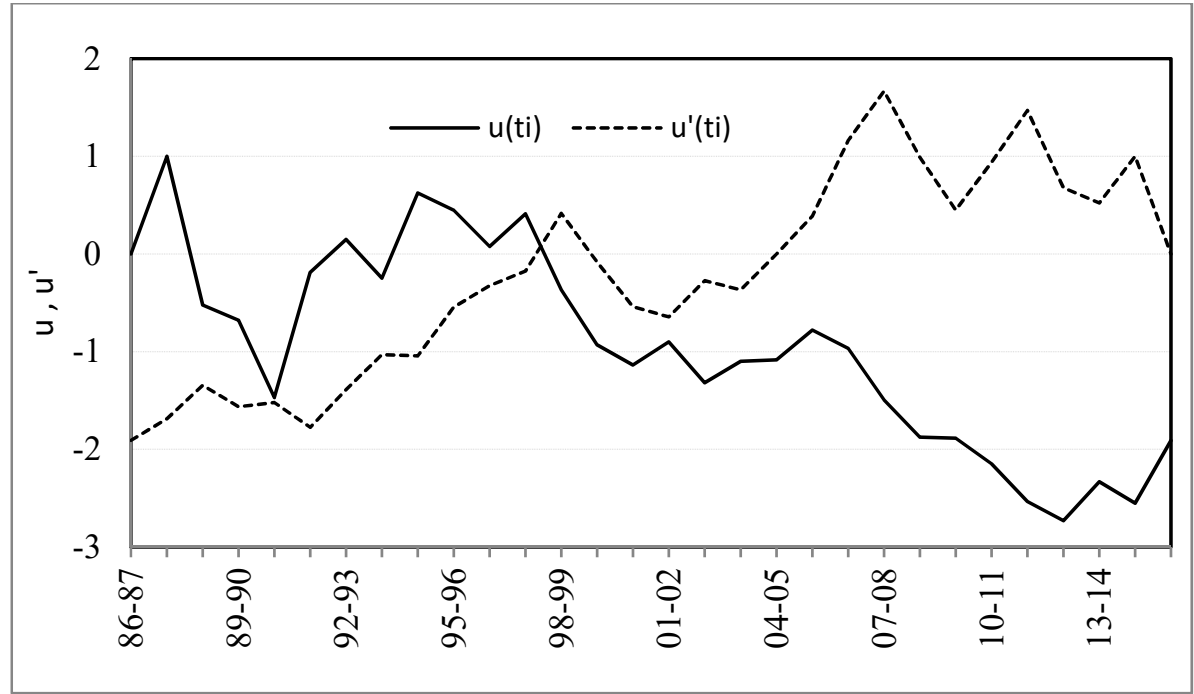

Fig 5. Trend and Change Point Analysis of Ilam Station by Sequential Mann-Kendal Method Annual Precipitation (1986-2016)

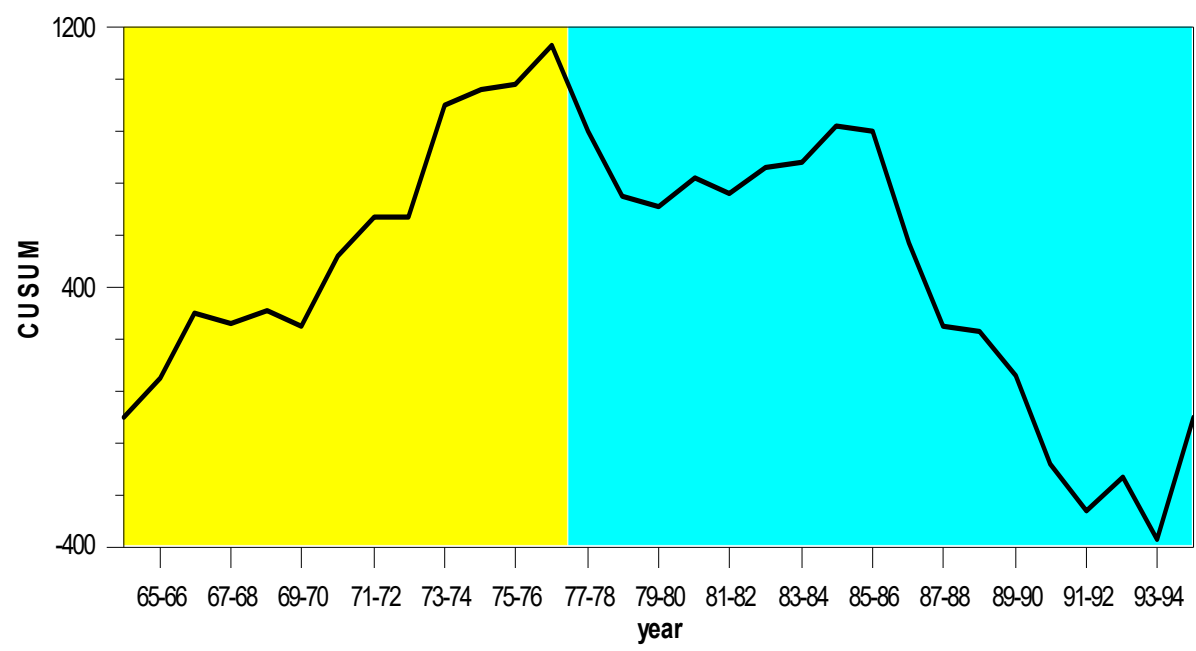

Fig 6. Annual precipitation change point of Ilam station by CUSCUM

*** (change point at 1377-78 in Solar Hijri Calendar equal to 1998-1999 to AD Calendar)

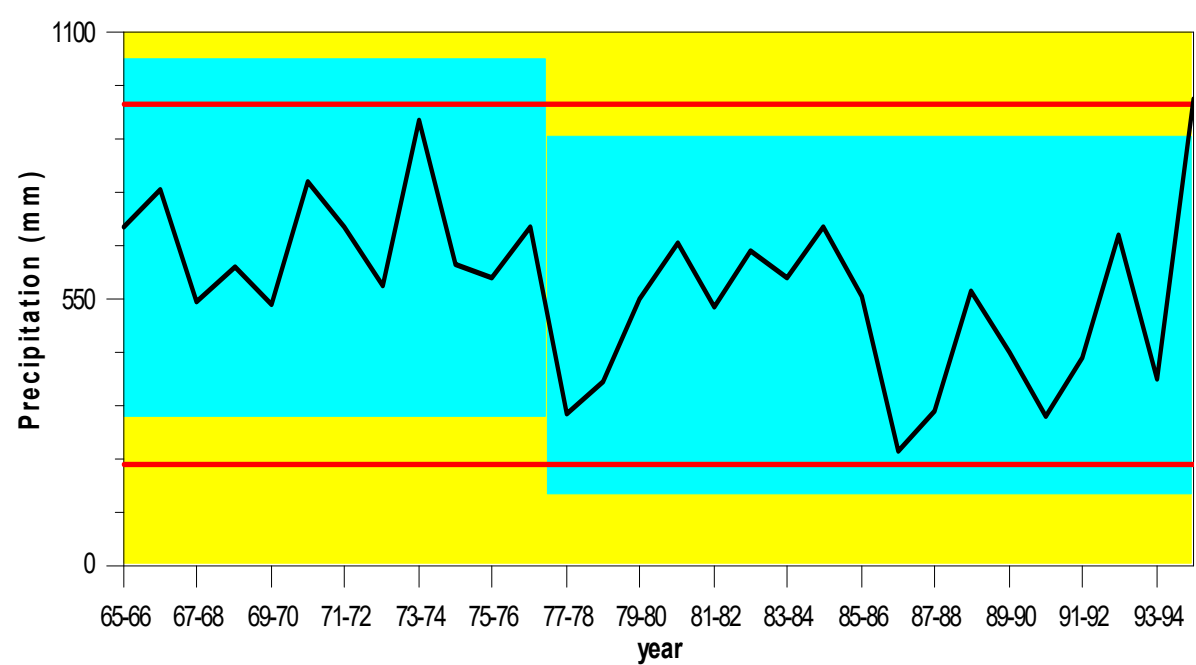

Fig 7. Analytical Chart of Annual Precipitation Change Point of Ilam Station (1365- 1395 to Solar Hijri Calendar) *** (change point at 1377-78 in Solar Hijri Calendar equal to 1998-1999 to AD Calendar) 
Tab 3. Results of Significant Changes for annual precipitation of Ilam station

\begin{tabular}{|c|c|c|c|c|c|}
\hline \multicolumn{6}{|c|}{$\begin{array}{c}\text { Table of Significant Changes for prec } \\
\text { Confidence Level for Candidate Changes }=95 \% \text {, Confidence Level for Inclusion in Table }=95 \%, \text { Confidence Intenal }=95 \% \text {, } \\
\text { Bootstraps }=1000 \text {, Without Replacement, CUSUM Estimates }\end{array}$} \\
\hline year & Confidence Interval & Conf. Level & From & To & Level \\
\hline $77-78$ & $(75-76,86-87)$ & $99 \%$ & 670.46 & 512.2 & 1 \\
\hline
\end{tabular}

Note: year $=1998-1999$ and Confidence Interval =1996-97, 2007-8 (A.D Calendar)

\section{Khorramabad Station}

In this station and with the complete statistical time period of $1951-2016$ (equivalent to $1330-1395$ in Solar Hijri Calnedar), downward trend was seen in annual precipitation using sequential Mann-Kendall method and the water year 1996 - 1997 was also the change point of time series with low to moderate probability (Figure 8.). However, using cumulative sum control chart and analytical methods that have been presented in Figures 9 and 10 and Table 4, the annual data of Khorramabad station lacked any significant change points.

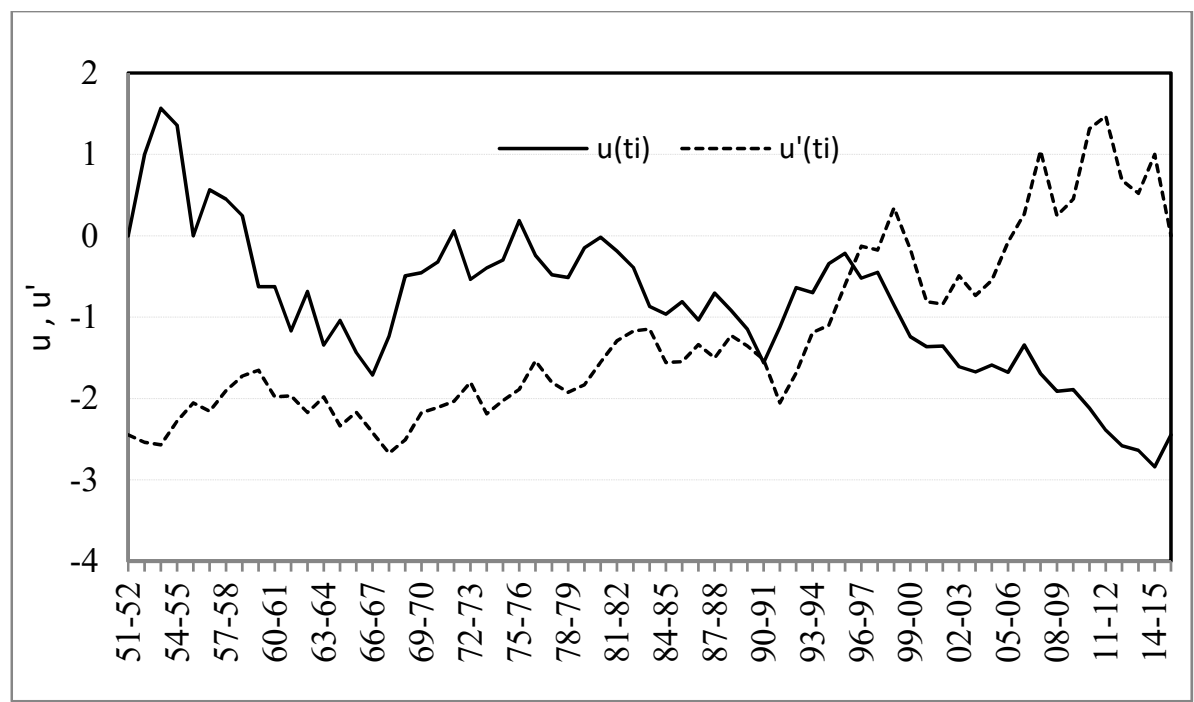

Fig 8. Trend and Change Point Analysis of Khoramabad Station by Sequential Mann-Kendal Method Annual Precipitation (1951-2016)

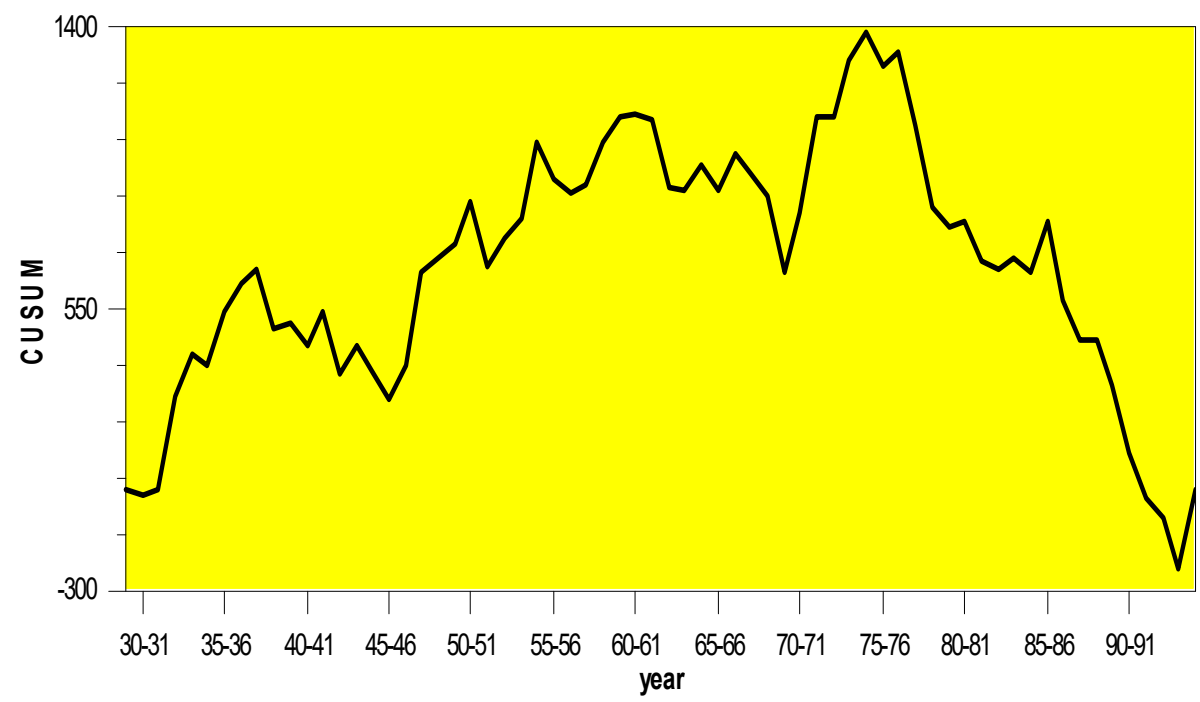

Fig 9. Annual precipitation change point of Khoramabad station by CUSCUM (equal to 1951-2016 A.D calendar) 


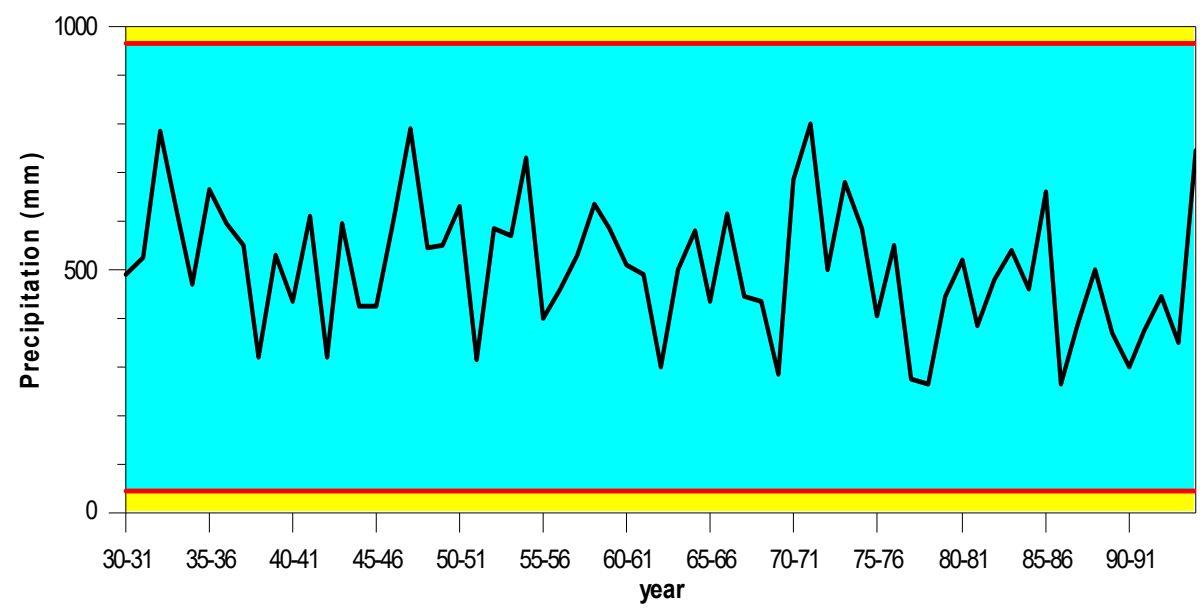

Fig 10. Analytical Chart of Annual Precipitation Change Point of Khoramabad Station (equal to 1951-2016 A.D calendar)

Tab 4. Results of Significant Changes for annual precipitation of Khoramabad station

No Significant Changes for prec
Confidence Level for Candidate Changes $=95 \%$, Confidence Level for Inclusion in Table $=95 \%$, Confidence Interval $=95 \%$,
Bootstraps $=1000$, Without Replacement, CUSUM Estimates
Estimated Average $=503.27015$

t should be noted that Khorramabad station has been in one place since its inception to the year 1978 and after that, has been relocated to a new and current location. Calculations related to the trend analysis and detecting change points were done in the both time series (1951 - 1978) and (1979 - 2016) with no significant trends and change points of annual precipitation in the first time series. But, in the second time series, considering Figure 11, there was a decreasing trend in annual precipitation on the basis of sequential Mann-Kendall test and the water year 2004 - 2005 has been introduced as the change point with moderate probability. However, there was no change points using cumulative sum control chart and analytical methods, the results of which, have been reflected in Figures 12 and 13 and Table 5.

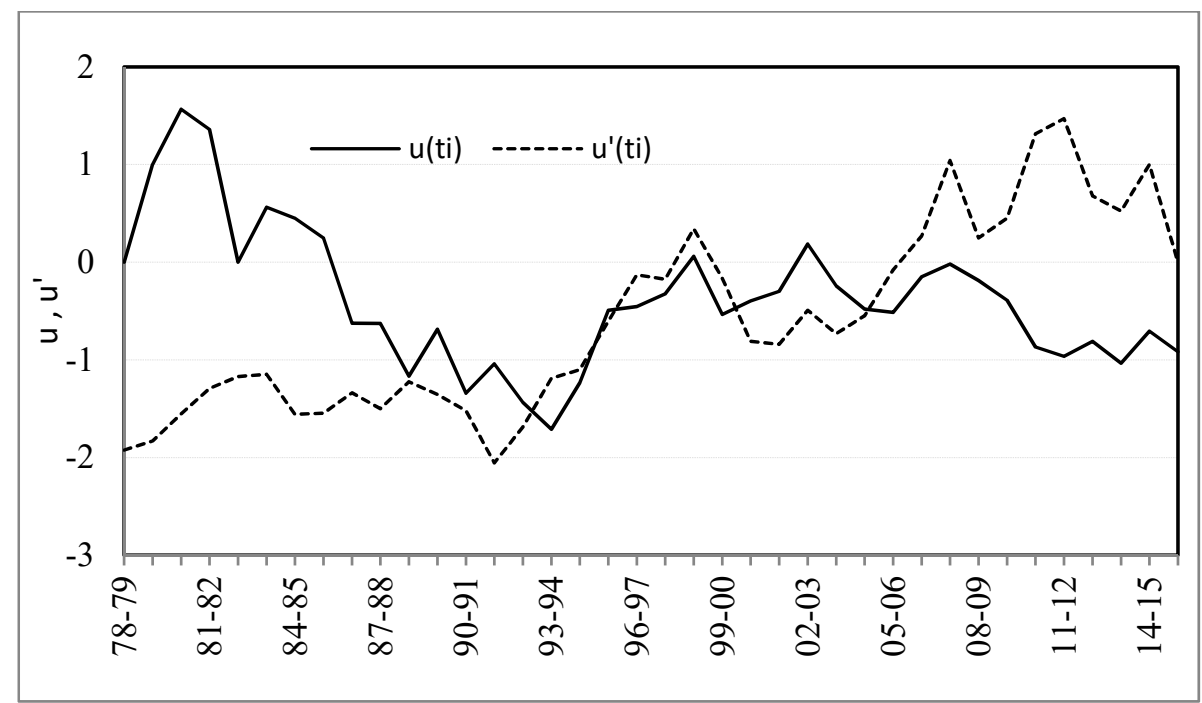

Fig 11. Trend and Change Point Analysis of Khoramabad Station by Sequential Mann-Kendal Method Annual Precipitation (1978-2016) 


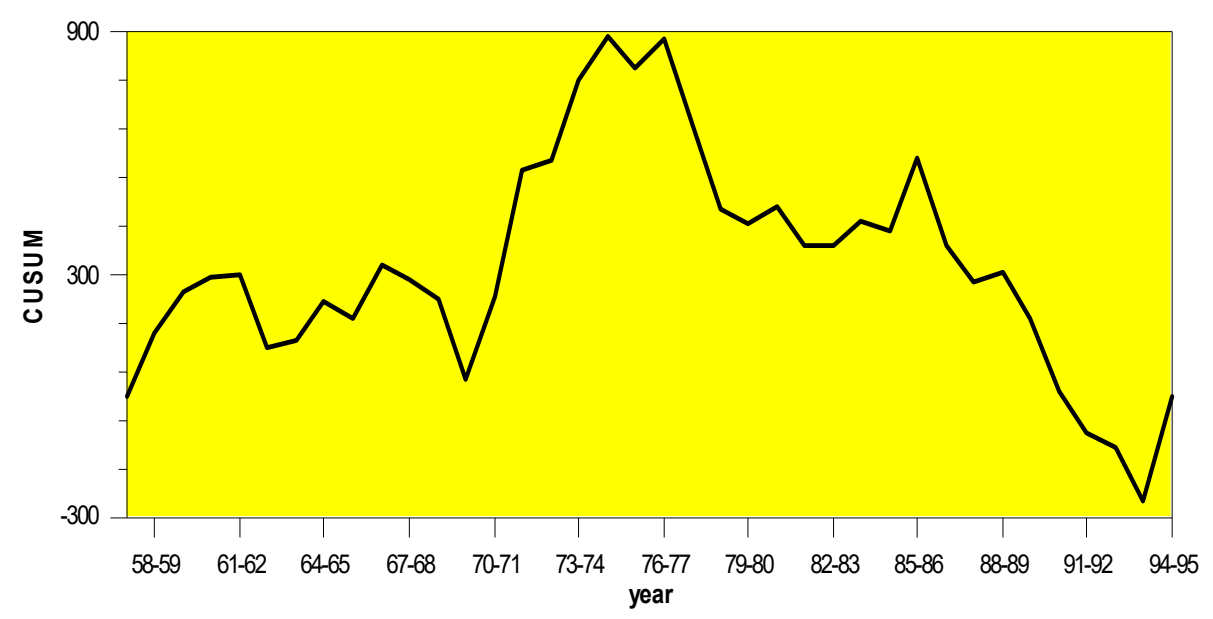

Fig 12. Annual precipitation change point of Khoramabad station by CUSCUM (equal to 1978-2016 A.D calendar)

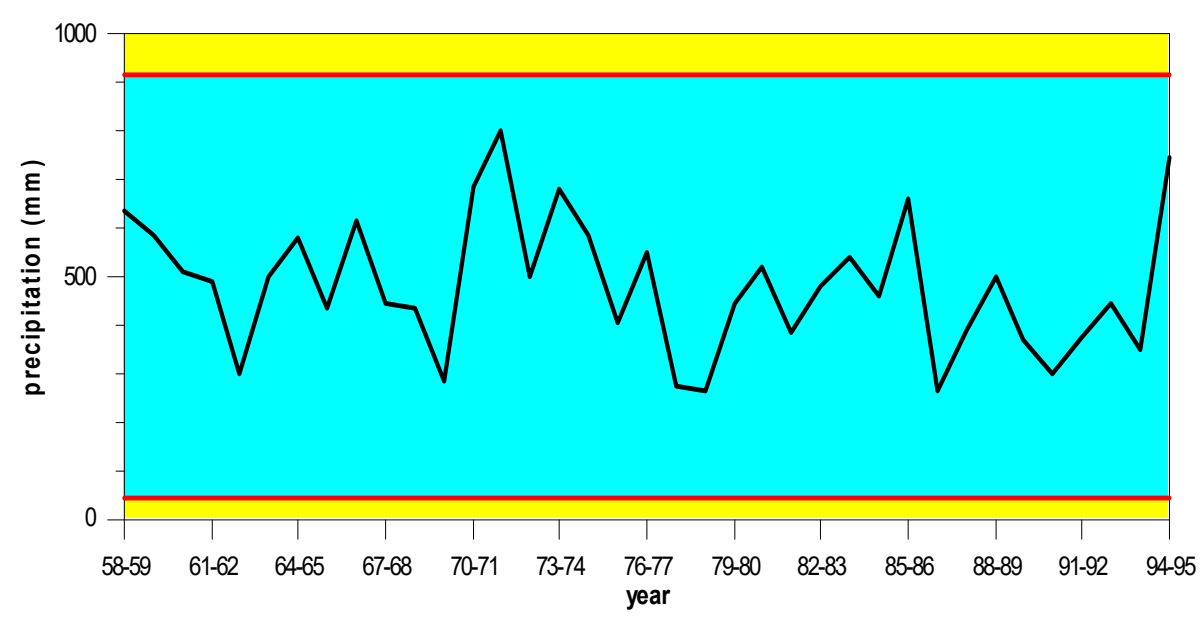

Fig 13. Analytical Chart of Annual Precipitation Change Point of Khoramabad Station (equal to 1978-2016 A.D calendar)

Tab 5. Results of Significant Changes for annual precipitation of Khoramabad station

No Significant Changes for precipitation
Confidence Level for Candidate Changes $=95 \%$, Confidence Level for Inclusion in Table $=95 \%$, Confidence Interval $=95 \%$,
Bootstraps $=1000$, Without Replacement, MSE Estimates
Estimated Average $=478.50162$

\section{Sanandaj Station}

The results of analyzing time series of the data of this station that have also been shown in Figure 14 using sequential Mann-Kendall method, suggested the downward trend in annual precipitation. In the case of change points, the results of which have been reflected in Figures 15 and 16 and Table 6, the years 1998 - 1999 were identified using analytical and cumulative sum control chart, and the years 1987 - 1988 were identified using sequential Mann-Kendall method in which the first two methods yielded more satisfactory results. 


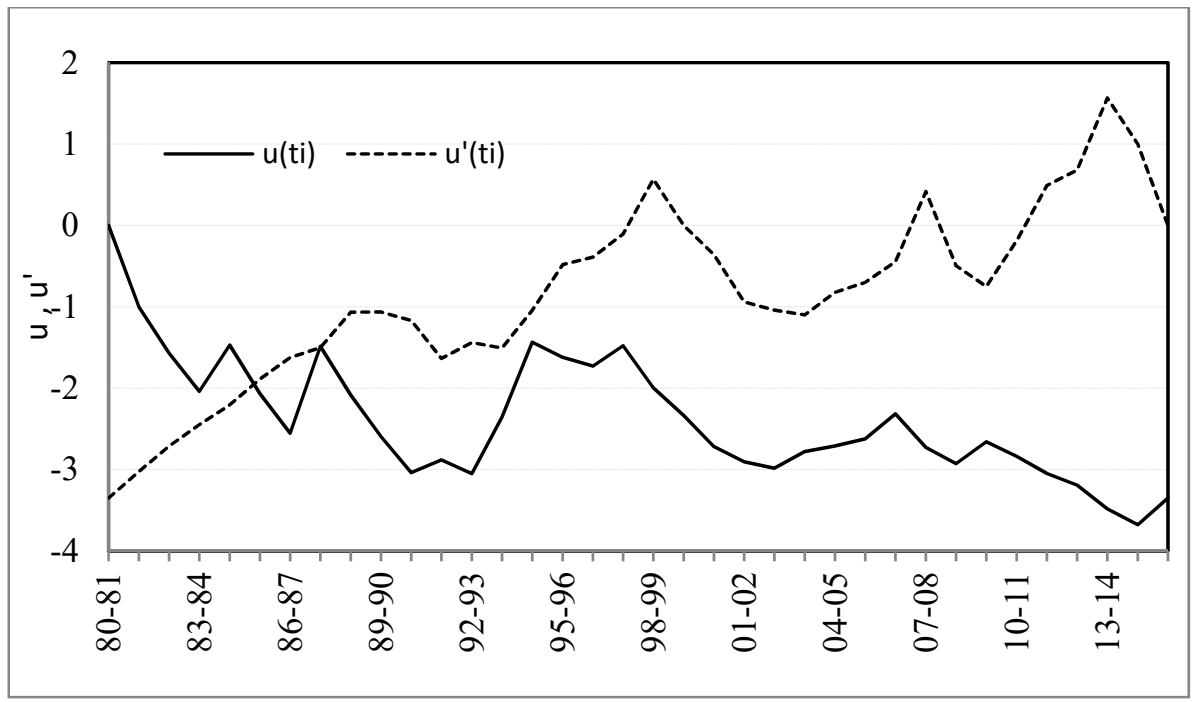

Fig 14. Trend and Change Point Analysis of Sanandaj Station by Sequential Mann-Kendal Method Annual Precipitation (1980-2016)

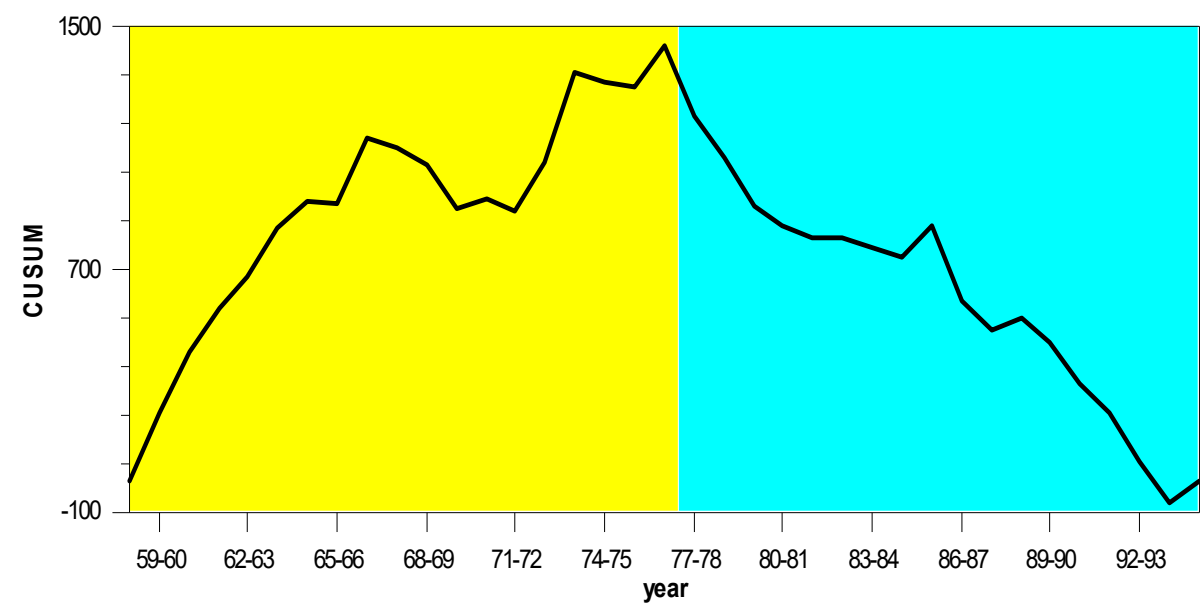

Fig 15. Annual precipitation change point of Sanandaj station by CUSCUM

*** (change point at 1377-78 in Solar Hijri Calendar equal to 1998-1999 to AD Calendar)

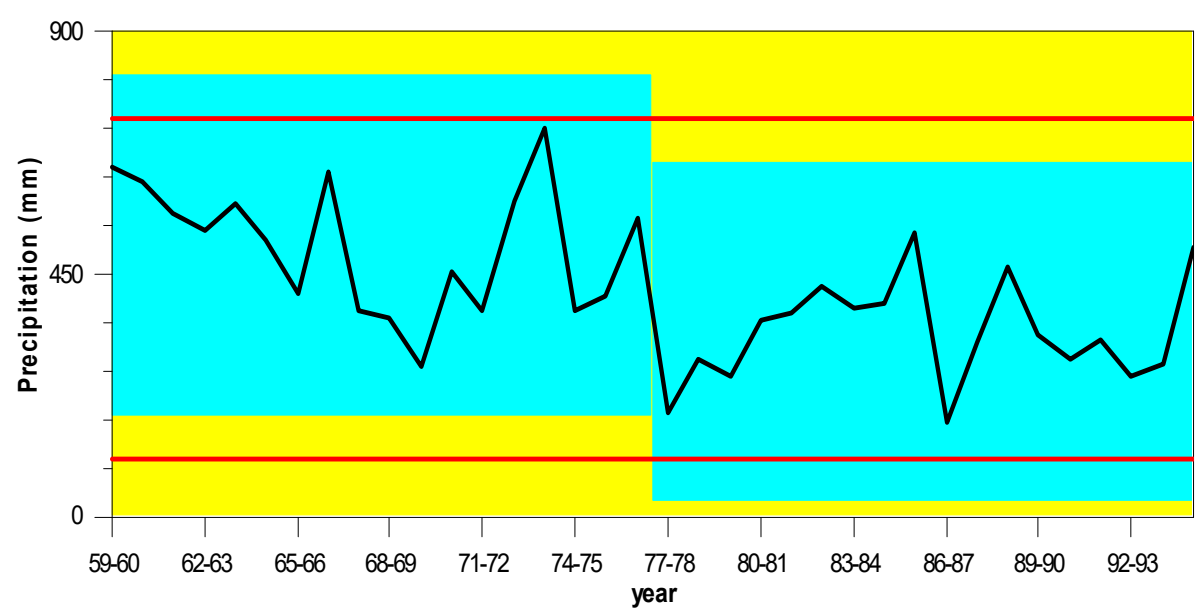

Fig 16. Analytical Chart of Annual Precipitation Change Point of Sanandaj Station *** (change point at 1377-78 in Solar Hijri Calendar equal to 1998-1999 to AD Calendar) 
Tab 6. Results of Significant Changes for annual precipitation of Sanandaj station

\begin{tabular}{|c|c|c|c|c|c|}
\hline \multicolumn{7}{|c|}{$\begin{array}{l}\text { Table of Significant Changes for prec } \\
\text { Confidence Level for Candidate Changes }=95 \% \text {, Confidence Level for Inclusion in Table = 95\%, Confidence Interval = 95\%, } \\
\text { Bootstraps }=1000 \text {, Without Replacement, MSE Estimates }\end{array}$} \\
\hline year & Confidence Interval & Conf. Level & From & To & Level \\
\hline $77-78$ & $(70-71,81-82)$ & $100 \%$ & 499.67 & 340.97 & 1 \\
\hline
\end{tabular}

Note: year =1998 -1999 and Cnofidence Interval =1991-92, 2002-3 (A.D Calendar)

\section{Hamedan Station (Shahid Nozheh airport)}

Trend analysis using sequential Mann-Kendall test in this station that has been presented in Figure 17, suggested the lack of trend with no changes in the observed time series. The Figures 18 and 19, in relation to cumulative and analytical chart and Table 7, indicate the lack of change points.

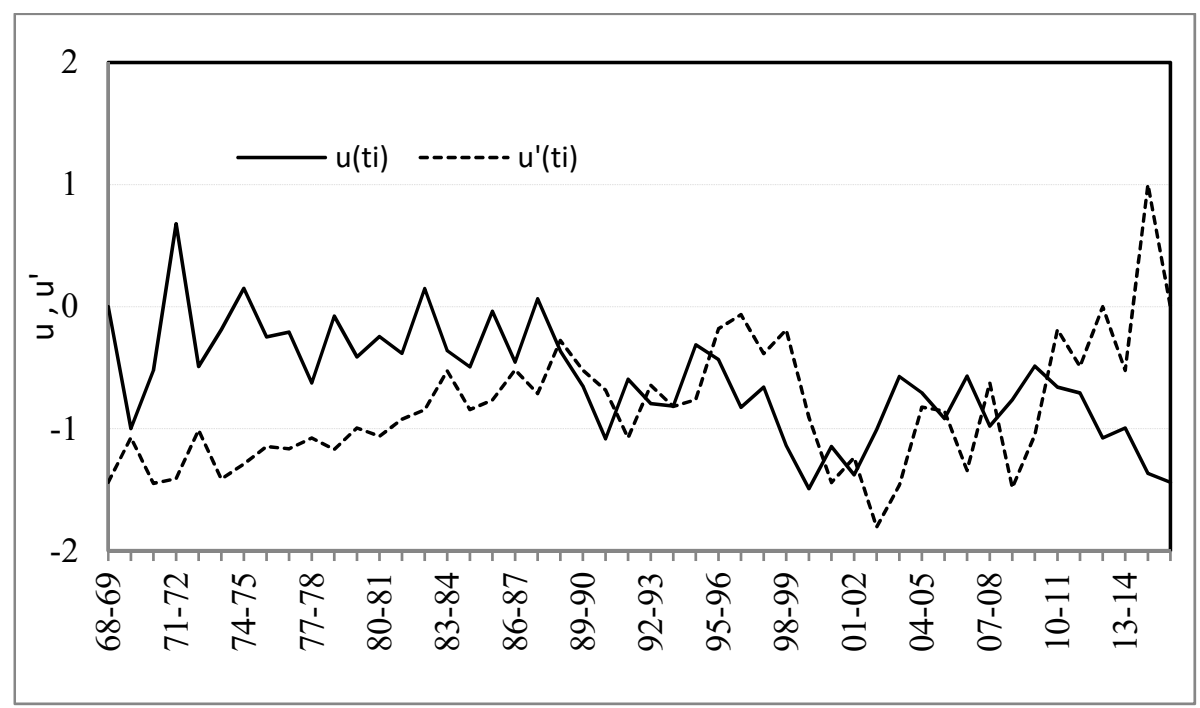

Fig 17. Trend and Change Point Analysis of Shahid Nozhe hamedan airport Station by Sequential Mann-Kendal Method Annual Precipitation (1968-2016)

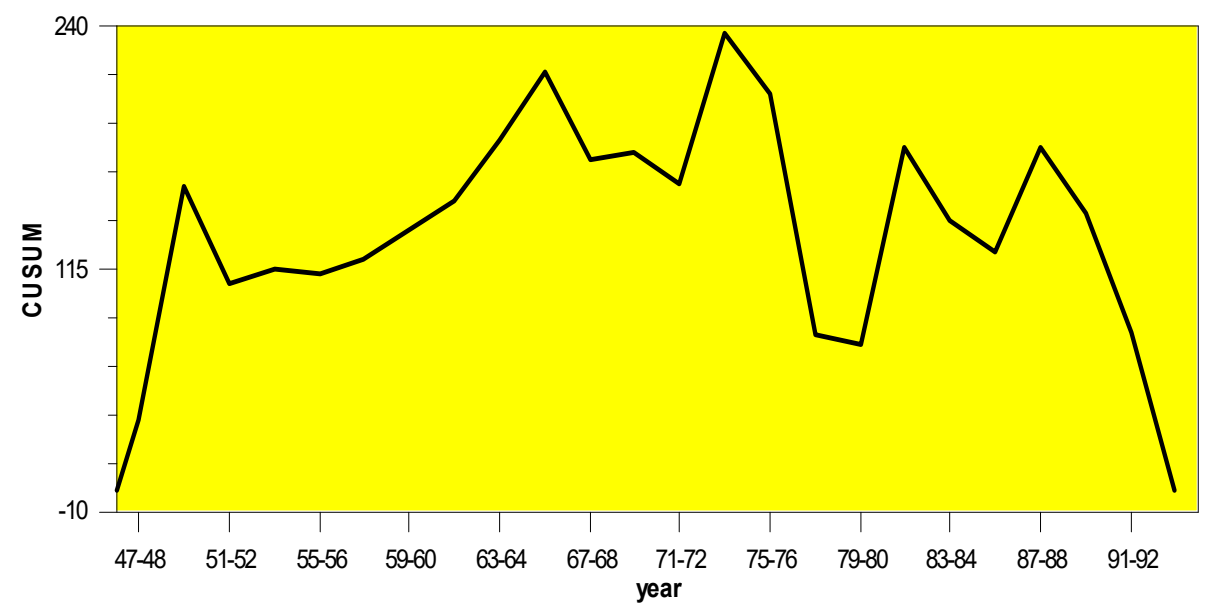

Fig 18. Annual precipitation change point of Shahid Nozhe hamedan airport station by CUSCUM (Solar Hijri calendar) 


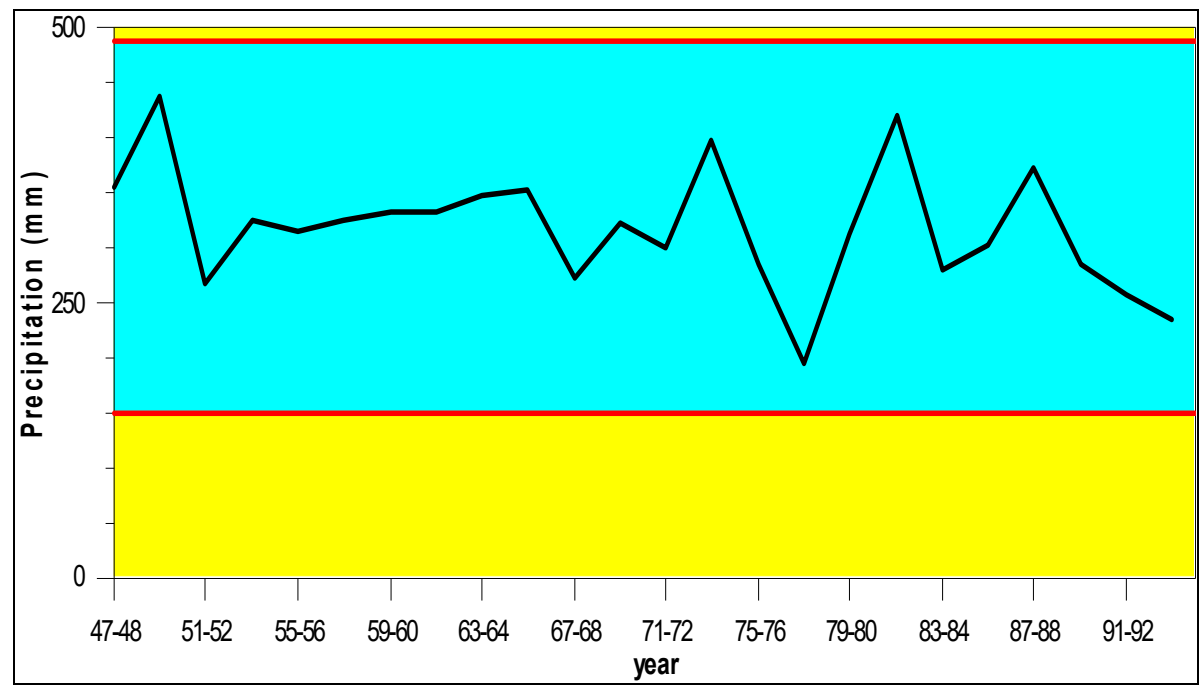

Fig 19. Analytical Chart of Annual Precipitation Change Point of Shahid Nozhe hamedan airport Station

Tab 7. Results of Significant Changes for annual precipitation of Shahid Nozhe hamedan airport station

No Significant Changes for prec
Confidence Level for Candidate Changes $=$ 95\%, Confidence Level for Inclusion in Table $=95 \%$, Confidence Intenal $=95 \%$,
Bootstraps $=1000$, Without Replacement, MSE Estimates
Estimated Average $=316.70417$

\subsection{Discussion and Conclusion}

In this research, the detection of change points in the time series of annual precipitation data of some of the stations in western provinces of Iran including Kermanshah, Ilam, Lorestan, Kurdestan, and Hamadan provinces were discussed. This study was initiated considering the fluctuations of two decades in the amount and time of precipitation in Western Iran and also given the significance of this region in supplying water for the dams of Khuzestan province for energy and drinking water consumption. On the subject of detecting change points, cumulative sum chart and analytical method as well as sequential Mann-Kendall test were used. With regard to the respective calculations, the conclusion of the simultaneous results of all stations are discussed annually in the geographical area covered by five stations mentioned below.

The results obtained from the trend analysis of annual precipitation using sequential Mann-Kendall test indicated that only Sanandaj station had a significant downward trend and in the case of Khorramabad, if its complete statistical period (1951 - 2016) was considered after the relocation of the station, a downward trend could be observed. However, using ranked Mann-Kendall method, Khorramabad station had no significant trends in precipitation under no circumstances (complete statistical period and before or after relocation) (Beedel, 2017). Therefore, relocation of a station (here, Khorramabad), is a point at issue in addressing data time series and similar research. The status of Sanandaj station and its exceptionality requires further research and the reasons for the downward trend could not be definitely explained.

Change points obtained using analytical and CUSUM methods as well as sequential Mann-Kendall test are present in Kermanshah station related to years (1996 - 1997) and (2005 - 2006), Ilam station (1998 - 1999) and (1998 1999), Khorramabad station with complete statistical period (1996 - 1997) and the period after the relocation of station (2004 - 2005), and Sanandaj station (1998 - 1999) and (1987 - 1988), while their trend was significant only in Khorramabad and Sanandaj stations and this would indicate that the western half of the studied area was different in terms of fluctuations in water year precipitation. While confirming the results of trend analysis, the analysis of change points demonstrated that despite differences and similarities that exist at the time of the occurrence of change points between stations, these years had clear overlapping with the periods of highest maximum temperature (year 1998) and highest drought and water stress (2007 - 2008) and the highest frequency of temperature change points (1998) with the frequency of 75\%. Furthermore, the water years of $1996-1997$ and 1998 - 1999 were associated with moderate to severe drought conditions between stations (Beedel, 2017). Hence, it could represent a kind of coordination in the synchronization and adaptation of precipitation downward trend and temperature accelerating trend. Another point at issue that could be somehow a matter of concern, was the decrease in the amount of recorded rainfall in some of the months of stations in relation to their long-term average 
that may increase the likelihood of change points and could actually initiate changes in precipitation behavior and the location and timing of rainwater systems deployment that should be strongly considered and appropriate measures ranging from research and management measures, should be considered to prevent surprise and exposure to rainfall deficits in Western Iran. Of course, according to the results of this study, water budget or the atmospheric precipitation of stations received per capita, did not show any downward trends except for Hamadan station. Therefore, the available amount of rainfall in the western part of the country, despite deficiency in some months, has not been so deficient and it could be offset by the implementation of modern and intelligent irrigation methods in agricultural sector and even urban and industrial consumption because the objective of the optimal management of surface and groundwater resources is actually to compensate for the scarcity of different uses at different times of the year.

[1] Aesawy, A.M., H.M. Hassanean . 1998. Annual and seasonal climatic analysis of surface air temperature variations at six southernMediterranean stations. Theor Appl Climatol. 61:55-68.

[2] Alexandersson,H. 1986. A Homogeneity Test Applied to Precipitation Data, Journal of climatology, 6(6): 661-675.

[3] Aminikhanghahi. S., D. J. Cook.2017. A Survey of Methods for Time Series Change Point Detection, Knowl Inf Syst. 51(2): 339-367.

[4] Anderson, T.W. andD.A. Darling,. 1954. A Test of Goodness-of-Fit. Journal of the American Statistical Association. 49: 765-769.

[5] Asgari. E., R.Mostafazadeh, Kh. Haji.2019. Change point analysis of discharge time series in some hydrometric stations in Golestan Province. J. Env. Sci. Tech. 21(5):81-93.

[6] Beedel, R. 2017. Trend and change point analysis of temperature in west of Iran,Journal of Research in Ecology.5(2):1113-1140.

[7] Buishand,T.A. 1982. Some Methods for Testing the Homogeneity of Rainfall Records, Journal of Hydrology, 58(1): 11-27.

[8] Dibal N. P., M. Mustapha, T. M .Adegoke, A. M. Yahaya. 2017. Statistical Change Point Analysis in Air Temperature and Rainfall Time Series for Cocoa Research Institute of Nigeria, Ibadan, Oyo State, Nigeria. International Journal of Applied Mathematics and Theoretical Physics.3(4): 92-96.

[9] Dixon W.J. 1950. Analysis of extreme values. Annals of Math. Stat. 21: 488-506.

[10] Fearnhead. P.,G. Rigaill .2019. Changepoint Detection in the Presence of Outliers, Journal of the American Statistical Association, 114:525, 169-183.

[11] Fu.X., C.C. Kuo, T.Y.Gan . 2015. Change point analysis of precipitation indices of Western Canada. International Journal of Climatology,35(9): $2592-2607$.

[12] Gallagher C., R. Lund, M. Robbins . 2013 . Changepoint Detection in Climate Time Series with Long-Ter Trends. Journal of climate, 26. pp.4994-5006.Grubbs F.E. 1969. Procedures for detecting outlying observations in samples. Technometrics, 11(1): 1-21.

[14] Hamed K.H., A.R .Rao. 1998. A modified Mann-Kendall trend test forautocorrelated data. Journal of Hydrology.204: 182-196.

[15] Jarque, Carlos M.;K. Bera Anil. 1987. A test for normality of observations and regression residuals. International Statistical Review. 55 (2): $163-172$.

[16] Jianting, C., X. Jun, X. Chongyu, L. Lu, W. Zhonggen .2010. Spatial and temporal variability of daily precipitation in Haihe River basin, 1958-2007. J. Geogr. Sci. 20(2): 248-260.

[17] Khapalova E.A., V. K. Jandhyala, S. B. Fotopoulos .2013.Change-Point Analysis of Annual Mean Precipitation for Northern, Tropical and Southern Latitudes of the Globe in the Past Century.Journal of Environmental Statistics, 4(3):1-21.

[18] Kendall, M.G. 1975. Rank correlation methods.4th ed, London: Charles Griffin.

[19] Khosravi H., F. Sajedi Hosseini, M. Nasrollahi, H.R. Gharechaee . 2017. Trend analysis and detection of precipitation fluctuations in arid and semi-arid regions. Desert, 22(1): 77-84.

[20] Kundu, S.K., T.K .Mondal .2019. Analysis of long-term rainfall trends and change point in West Bengal, India, Theor Appl Climatol. 138(3-4): 1647-1666.

[21] Kürbis, K., M.Mudelsee, G. Tetzlaff and R.Brázdil .2009. Trends in extremes of temperature, dew point, and precipitation from long instrumental series from central Europe. Theor Appl Climatol 98:187-195.

[22] Li. M., J. Xia, Z. Chen, D. Meng and C. Xu .2013. Variation analysis of precipitation during past 286 years in Beijing area, China, using non-parametric test and wavelet analysis. Hydrol. Process. 27: 2934-2943.

[23] Lilliefors, H. 1967. On the Kolmogorov-Smirnov test for normality with mean and variance unknown, Journal of the American Statistical Association, 62: 399-402.

[24] Mann, H.B. 1945. Nonparametric tests against trend. Econometrica,13: 245-259.

[25] Neumann,J.V.1941. Distribution of the Ratio of the Mean Square Successive Difference to the Variance. Ann Math Stat. 13: 367-395.

[26] Palaniswami, S., K. Mutiah.2018. Change point detection and trend analysis of rainfall and temperature series over the Vellar river basin. Polish Journal of Environmental studies, 27(4):1673-1681.

[27] Pettitt,A.N.1979. A Non-Parametric Approach to the Change-Point Detection. Appl Stat. 28: 126-135.

[28] Sen, P.K. 1968. Estimates of the regression coefficient based on Kendall's tau. Journal of American Statistical Association. 39: 13791389.

[29] Shapiro, S. S., M. B. Wilk, and H. J. Chen. 1968. A comparative study of various tests for normality: J. Amer. Stat. Assoc., 63: 13431372.

[30] Sneyers, R., 1990. On the Statistical Analysis of Series of Observations. WMO. Technical Note (143).World Meteorological Organization, Geneve . (192 pp.).

[31] Shirvani, A. 2015(a). Change point detection of the Persian Gulf sea surface temperature. Theoretical and Applied Climatology. DOI: $10.1007 / \mathrm{s} 00704-015-1625-5$

[32] Shirvani A. 2015(b). Change point analysis of mean annual air temperature in Iran. Atmos. Res. 160: 91- 98.

[33] Siti ,A., M. Mohsin, M. Farhan,A. B. Azuraliza, H. Abdul, S. A. Sharifah. 2017. Change point analysis:A statistical approach to detect potential abrupt change. Jurnal Teknologi.79(5):147-159.

[34] Soltani. M., I. Rousta and Sh. S. Modir Taheri. 2013. Using Mann-Kendall and Time Series Techniques for Statistical Analysis of LongTerm Precipitation in Gorgan Weather Station, World Applied Sciences Journal. 28 (7): 902-908.

[35] Suh.M.S.,Ch. Kim .2015.Change-Point Analysis of Tropical Night Occurrences for Five Major Cities in Republic of Korea, Advances in Meteorology,Vol. 2015: 11 pages.

[36] Taylor,W.A.2000. Change-Point Analysis: A Powerful Tool for Detecting Changes, preprint available as http://www. variation. com/cpa/tech/changepoint. html.

[37] Yu. M.,E Ruggieri.2019. Change point analysis of global temperature records. International Journal of Climatology,39( 8): 3679-3688. 
[38] Yogesh . R., W. Abhishek, R. Ravindra, K. Nidhi. 2018. Trend analysis and change point detection of rainfall for Andhra Pradesh and Telangana, India. Journal of agrometeorology, 20(2):160-163.

[39] Zarenistanak. M., A.Dhorde, R. Kripalani. 2014. Trend analysis and change point detection of annual and seasonal precipitation and temperature series over southwest Iran.Journal of Earth System Science, 123(2):281-295.

[40] Zhou C., R.V. Nooijen, A. Kolechkina, M. Hrachowitz . 2019. Comparative analysis of nonparametric change-point detectors commonly used in hydrology, Hydrological Sciences Journal, 64(14):1690-1710. 